\title{
Selection of extreme drought event for Langat Basin and its consequence on salinity intrusion through Langat River System
}

\author{
Md Mobassarul Hasan ${ }^{1}$, Morsheda Begum², Abdullah Al Mamun ${ }^{3}$ and Zahirul \\ Haque $\mathrm{Khan}^{4}$ \\ ${ }^{1,2} \& 4$ Coast Port and Estuary Management Division, Institute of Water Modelling, Bangladesh \\ ${ }^{3}$ Hydrology and Hydraulics Division, Jurutera Perunding Zabba SDN. BHD. , Malaysia
}

\begin{abstract}
Langat River is located in a financial strategic place in Malaysia where a number of industries have been developed over the time. All of them are completely depended on Langat River for water supply and navigation. Besides, the river water is also used for different purposes such as domestic use, agriculture, fisheries etc. Therefore, the quality (salinity level)and quantity ofthe river water is very important for the country from financial point of view and that is why the assessment of salinity level in the river system is essential for severe low flow event such as extreme drought condition. The assessment of salinity intrusion during extreme drought condition requires use of scientifically based and tested state-of-the-art mathematical modelling tools. This paper presents the selection of extreme drought event through Stream Flow Drought Index (SDI) and the assessment of salinity intrusion through Langat River system using such tested modeling tools. Three different models namely Hydrological, Hydrodynamic and Salinity models were developed and calibrated under this study to assess the salinity intrusion through Langat River. The study determines the extreme drought year as 1998 and 2010. All the models were simulated for2009 (an average condition), 1998 (extreme drought), 2010(extreme drought) and no flow from upstream. The results show that the Langat River is not vulnerable for salinity intrusion for any kind of extreme drought event but if there is no flow from upstream 1ppt saline line may intrude more $9 \mathrm{~km}$ towards upstream.
\end{abstract}

Keyword:Langat River, Stream Flow Drought Index, Mathematical Modelling, Salinity Intrusion

\section{Introduction}

Langat River basin is one of the most important basin which supply water to two third of the sate of Selangor (area: $8104 \mathrm{~km}^{2}$ ) of Malaysia. However, rapid urbanization within Langat River basin due to changes in economy policies by Malaysian Government, involved the changes in land use activities [1]. There are lots of industries have been developed on the bank of the river over the time and they completely depend onthis river for their water demand and navigation. On the other hand the river water is also used for different purposes such as domestic, agriculture, fisheries etc and that is why the quality (salinity level) and quantity of the river water is incredibly important for the country from a financial point of view. But this quality and quantity may hamper due to drought condition as Malaysia experiences quite frequent drought now-a-days. It is found from previous study that the state of Melaka faced critical water problems with water levels falling below critical levels due to drought in 1991 [2]. Whereas, in 1998, an El Nino related drought severely affected the states of Kedah, Penang and Selangor [3] and that had an extensive impact on the environment and society across the nation [4].The country also faced severe water crisis in February 2014 and most of the states including Selangor were also affected severely. It is evident that the salinity intrusion in a river is fully reliant on the upstream flow(rainfall runoff) pattern and during drought event there is a possibility of salinity intrusion towards upstream as there is less amount of water available at that period. Since Langat River is strategically an important river, it is indispensable to assess distribution of salinity level in Langat River during extreme drought event. The main objective of this study is to select an extreme drought event in Langat basin and its effect on salinity intrusion through LangatRiver system.

\section{Study area}

Sungai Langat is one of the prominent rivers in Malaysia and the river basin covers the state of Selangor and Negeri Sembilan and also a portion of Federal Territory of Putrajaya, Kuala Lumpur and Klang and Petaling Jaya district. The Northeastern part of the river basin is mountainous and has an average reduced level (RL) of $960 \mathrm{~m}$ above the mean sea level. The middle part of the basin has been characterized as hilly areas and has slope spreading widely from north to east. In this part, the RL is below $100 \mathrm{~m}$ and the foot of the hill extends to Putrajaya, Cyberjaya and Dengkil in Sepang. The lower part is alluvial plane, relatively flat and located southwest of the Langat basin. The climate of the study area is characterized by uniform high temperature, high humidity and heavy rainfall with two major monsoon seasons i.e., southeast and northeast monsoon. Average temperature of the study area varies from $23^{\circ} \mathrm{C}$ to $33^{\circ} \mathrm{C}$ all round the year whereas the 
relative humidity ranges from $96 \%$ to $62 \%$ and averaged around $82 \%$. However, the mean annual rainfall of the study area is about $2,400 \mathrm{~mm}$. Heavier rainfall occurs in the month of November, which has a monthly mean rainfall of $270 \mathrm{~mm}$. Besides the area also occasionally experiences rainstorms generated by local convection and these rainstorms normally occur in late afternoons throughout the year which are generally of short duration with high intensity.

\section{Methodology}

The steps of study methodology are furnished in the Figure 1. It is clear from the figure that data collection was the first and crucial stage because study outputs are completely depend on the quality of collected data. After that all the data were processed and analyzed as per model requirement. All the models namely Hydrological, Hydrodynamic and Salinity were then developed and calibrated as per JPS (Jabatan Pengarian Dan Saliran/Department of Irrigation and Drainage) guideline with primary and secondary data. Afterward extreme drought event was selected using the results of historical simulation of hydrological model. Finally all the models were simulated for the selected extreme event to assess the salinity intrusion through Langat River system.

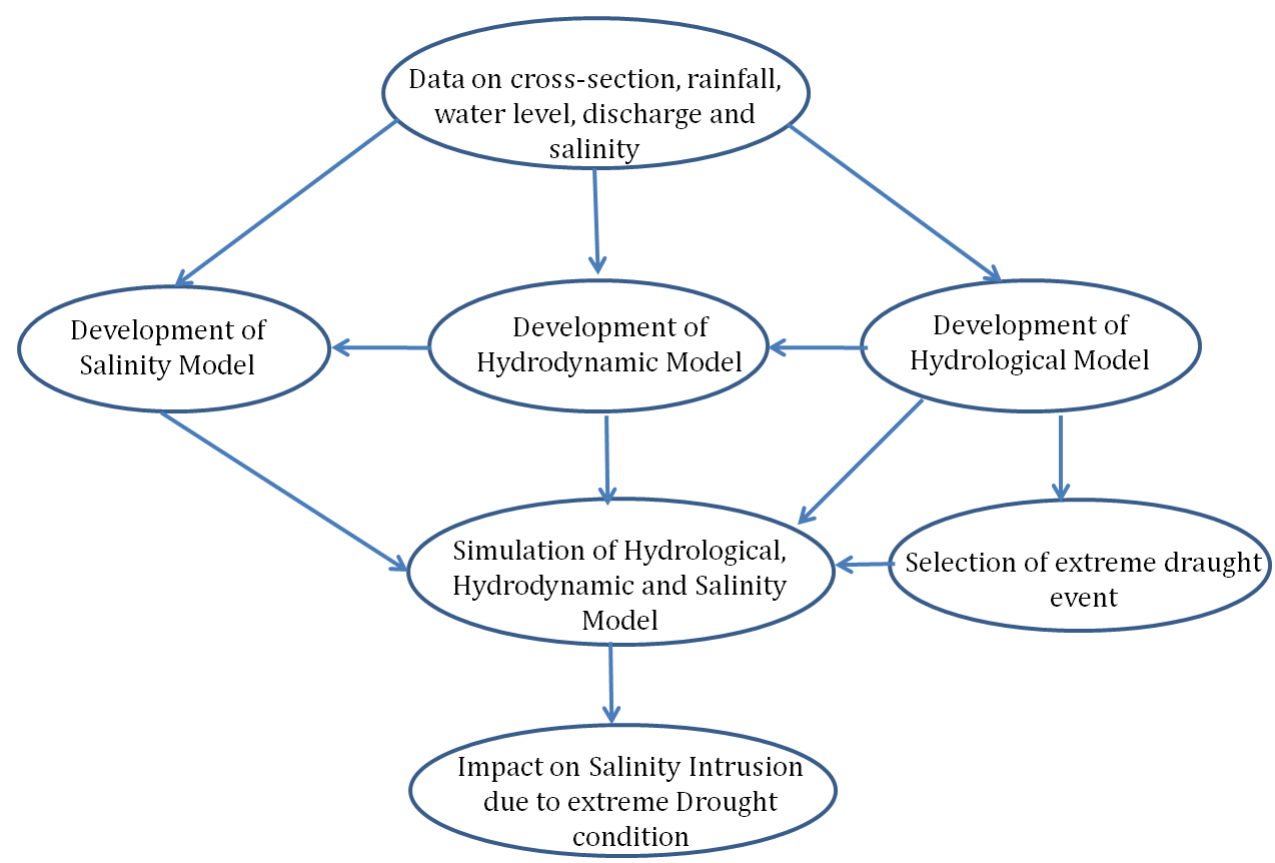

Figure 1: Flow diagram of study methodology

\section{Development of mathematical model \\ 1.1 Hydrological (Rainfall Runoff) Model \\ 1.1.1 Model set-up}

The hydrological model whichwas used for rainfall runoff modelling for Sg. Langat basin is the NAM model which is integrated within the NAM-MIKE 11 hydrological/and hydraulic modelling suite developed by the Danish Hydraulic Institute (DHI). The Sungai Langat has a catchment area of approximately $2400 \mathrm{~km}^{2}$ with tendominant rainfall stations and two evaporation stations within and adjacent to the river basin. At the beginning of the Rainfall Runoff Model, the whole catchment was divided into 28 sub-catchments according to land elevation. To distribute the rainfall data to different catchments, Thiessen Polygons were drawn using GIS software to calculate the weightage factors of different rainfall gauging stations for corresponding catchments. The Figure 2shows generated Polygons by Arc GIS along with catchment boundary and location of available rainfall stations. 


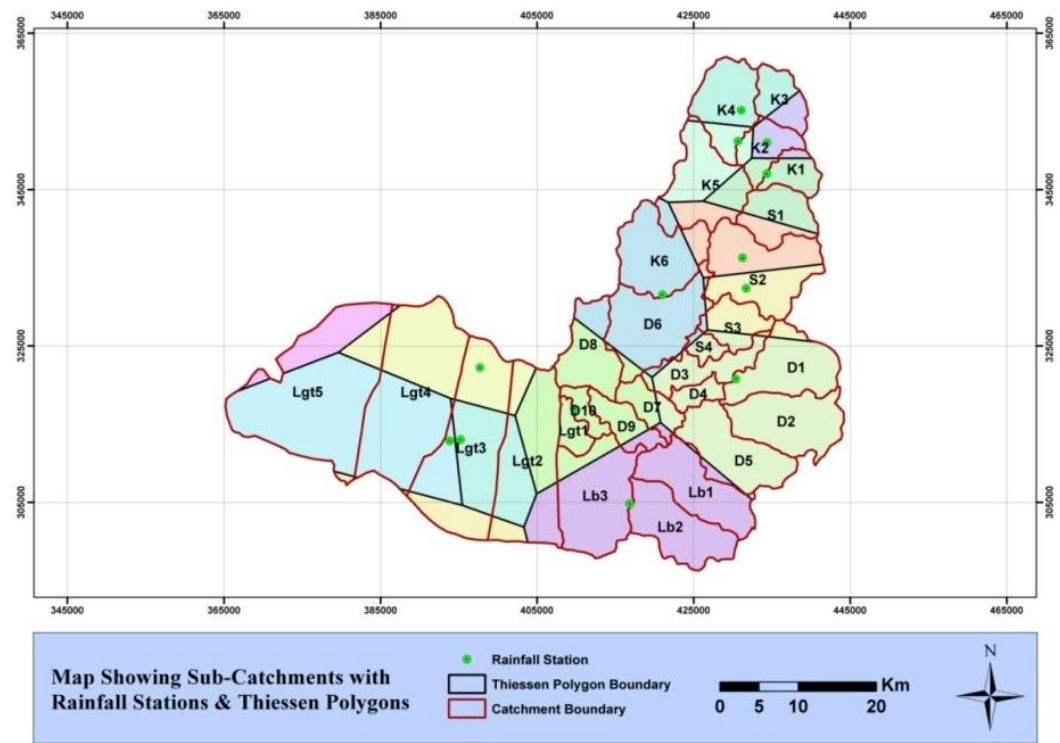

Figure 2: Generated thiessen Polygons along with catchment boundary

\subsubsection{Model Calibration}

Any hydrological model that uses the rainfall-runoff relationship method needs to be calibrated based on historical data. Flow data at Dengkil of Langat River was used to calibrate the Rainfall runoff model. The Dengkil station is located at the upstream of the Langat Riverwhere stream flow is available which drains runoff from seventeen upstream catchments. The calibration results of the rainfall runoff model at Dengkil are shown in Figure 3.The calibration result shows good agreement between observed and simulated results. However, few observed data do not match with the simulation results, which might be due to uncertainty in data and model parameters.

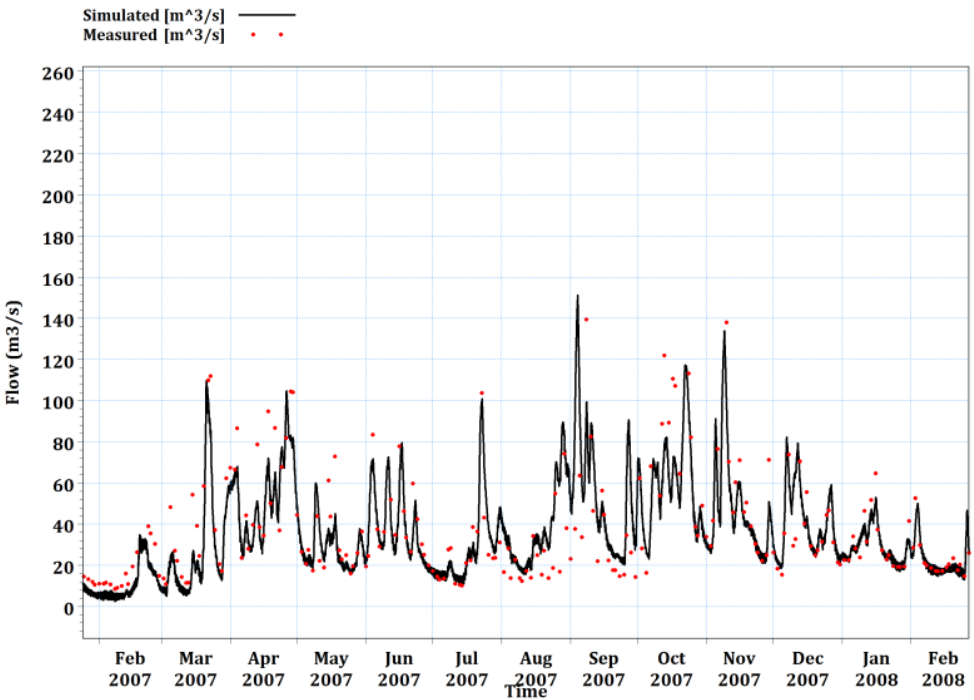

Figure 3: Calibration of Hydrological Model at Dengkil

\subsection{Hydrodynamic Model}

\subsubsection{Model set-up}

Hydraulic modelling is a proven and tested technology which can be applied in assessing any kind of impact assessment in any kind of water body. MIKE11 modelling system by DHI has been applied for hydraulic modelling in this study which is a user-friendly, fully dynamic, one-dimensional modelling tool for the detailed hydraulic analysis. The coverage of the modelling is selected considering the available cross section data, hydrological and meteorological condition of the river catchment and area of interest.

The locations of model boundaries are selected in such a way that possible uncertainties in applied boundary conditions do not affect the simulated conditions at the areas of interest and availability of required boundary data. The downstream boundaries are located at Light House and at the Port Klang where the 
predicted water level time series data were used. On the other hand the daily observed discharge at Dengkilwas used as upstream boundary.

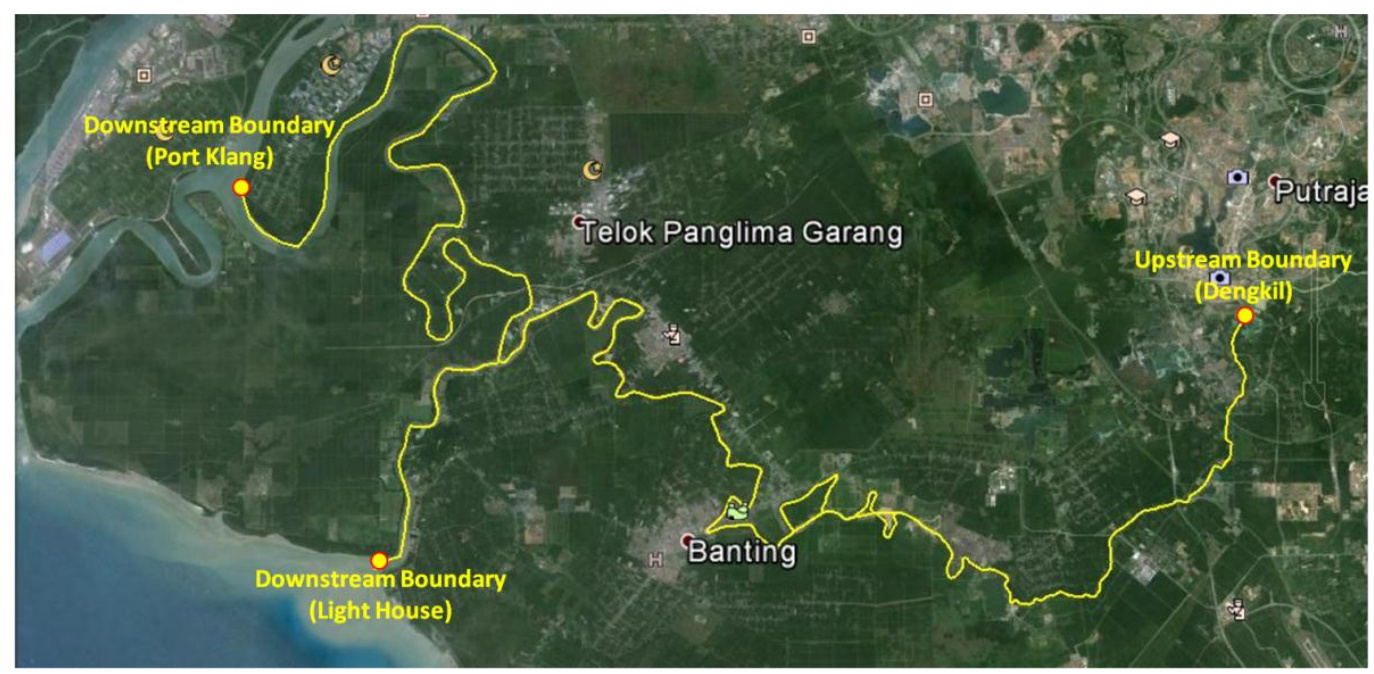

\subsubsection{Model calibration}

Figure 4: River network and boundary location

Comparison between measureddata and simulatedresults at different locationswere carried out using primary water level and current speed to make the hydrodynamic model more reasonable. It is important to calculate the calibration index to assess the reliability of model result. Table 1describes the correlation coefficients/calibration index (section 1.2.3) for all the calibration results with JPS guideline value. All the comparisons showgood agreement and almost support the JPS guideline. Now, the models are ready to be used for further option simulations.

Table 1:Quality Index for water level and current speed

\begin{tabular}{|c|c|c|c|c|}
\hline \multirow{2}{*}{ Station } & \multirow{2}{*}{ Data Type } & Tide Condition & Quality Index & $\begin{array}{c}\text { According to JPS } \\
\text { (Malaysia) }\end{array}$ \\
\hline \multirow{3}{*}{ Kg Sawah } & \multirow{2}{*}{ Current Speed } & Spring Tide & 0.69 & 0.7 \\
\cline { 3 - 5 } & \multirow{3}{*}{ Bater Level } & Neap Tide & 0.76 & 0.7 \\
\cline { 2 - 5 } & \multirow{2}{*}{ Current Speed } & Spring Tide & 0.98 & 0.9 \\
\cline { 3 - 5 } & & Neap Tide & 0.68 & 0.7 \\
\cline { 2 - 5 } & Water Level & & & 0.7 \\
\hline \multirow{3}{*}{ Megasteel } & \multirow{2}{*}{ Current Speed } & Spring Tide & 0.73 & 0.7 \\
\cline { 2 - 5 } & & Neap Tide & 0.58 & 0.7 \\
\cline { 2 - 5 } & Water Level & & 0.98 & 0.9 \\
\hline
\end{tabular}

\subsubsection{Mathematical Background of Quality Index}

The quality indices used for comparing measurements, $m e$, with values computed with a hincast/forecast model, mo are

- $\quad$ Bias

- $\quad R M S$

- $\quad$ Bias Index, $B I$

- $\quad$ Scatter Index, $S I$

- $\quad$ And the correlation coefficient, $\rho$

For each valid measuremt, $m e_{i}$, measured at time $t_{i}$, the corresponding model value, $m o_{i}$, is extracted from the model results, using linear interpolation between the model timesteps before and after $t_{i}$ The quality indices are calculated as follows: 


$$
\begin{aligned}
& m e_{i} \quad \text { Measured Value } \\
& m_{i} \quad \text { Model Value } \\
& d i f_{i}=m o_{i}-m e_{i} \\
& \overline{m e}=\frac{1}{N} \sum_{i=1}^{N} m e_{i} \\
& \text { bias }=\overline{d i f}=\frac{1}{N} \sum_{i=1}^{N} d i f_{i} \\
& R M S=\sqrt{\frac{1}{N} \sum_{i=1}^{N} d i f_{i}^{2}} \\
& B I=\frac{\text { bias }}{\overline{m e}} \\
& S I=\frac{R M S}{\overline{m e}} \\
& \rho=\frac{\sum_{i=1}^{N}\left(m e_{i}-\overline{m e}\right)\left(m o_{i}-\overline{m o}\right)}{\sqrt{\sum_{i=1}^{N}\left(m e_{i}-\overline{m e}\right)^{2} \sum_{i=1}^{N}\left(m o_{i}-\overline{m o}\right)^{2}}}
\end{aligned}
$$

\section{Notes to the quality parameters}

\section{- $\quad$ The bias is the mean error}

- $\quad R M S$ is the Root Mean Square error. The RMS is not corrected for the bias, and unless the bias is insignificant this parameter is difficult to interpret.

- $\quad B I$ is a non-dimensional bias

- $\quad S I$, the Scatter index, is a non-dimensional $R M S$

- $\quad \rho$, is the correlation coefficient between two stochastic variables. The correlation co-efficient reflects the degree to which the variation of the first is reflected in the variation of the other variable.

\subsection{Salinity Model}

\subsubsection{Model set-up}

The salinity model has been set-up applying Advection and Dispersion Module of the MIKE11 Modelling System. It solves the Advections Dispersion equations.

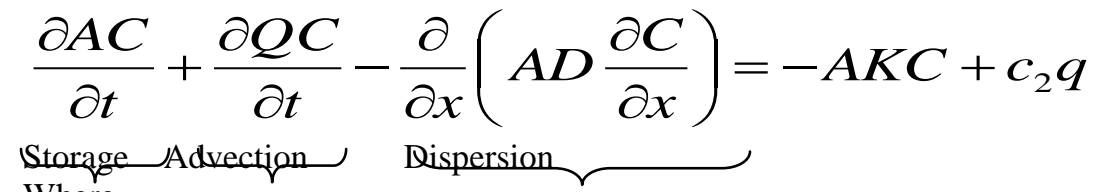

Where,

$C$ : concentration

$D$ : dispersion coefficient

$A$ : cross-sectional area

$K$ : linear decay coefficient

$C 2$ : source/sink concentration

$q$ : lateral inflow

$x:$ space coordinate

$t$ : time coordinate

Advection is a transport mechanism of a substance or a conserved property with a moving fluid. Dispersionis a system in which particles are dispersed in a continuous phase of a different composition

Steps were followed in salinity modelling are illustrated below;

- $\quad$ Need well calibrated and validated HD model

- $\quad$ Advection and dispersions parameter

- Salinity Boundary condition

- $\quad$ Appropriate Initial condition 
- $\quad$ Simulation of salinity intrusion

- Calibration

The model set-up for salinity model is almost same as hydrodynamic model. The new additionsin this module are the salinity boundary condition and advection-Dispersion parameters. The upstream of the model is at Dengkil where there is no salinity in the river and that is why the salinity boundary condition at Dengkil is considered as $0 \mathrm{ppt}$ whereas the downstream boundaries of the model are at the sea and the sea salinity $32 \mathrm{ppt}$ is considered for the downstream boundary.

\subsubsection{Model calibration}

The Model was calibrated at twelve kilometer upstream from the outfall of the river which is shown in the Figure 5. It shows quite good agreement between measured and simulated data and the model can be used for further assessment.

Measured [PSU] • $\bullet$

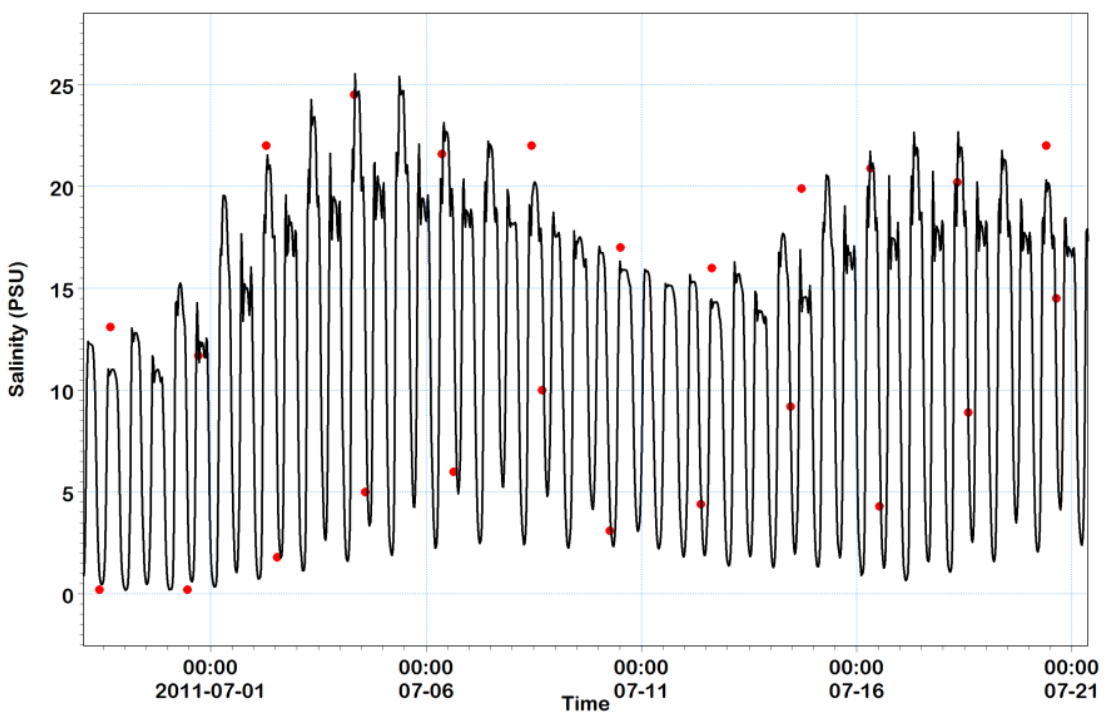

Figure 5: River network and boundary location

\section{Selection of draught event}

Drought is a naturally occurring phenomenon related to a significant decrease of water availability during a significant period of time and over a large area. It affects man's economic activities, human lives and various elements of the environment such as the Earth's ecosystem. The origin of drought is impossible to define much as the starting point of the global hydrological cycle. Conventionally, decrease of precipitation is considered as the origin of drought. This leads to a reduction of storage volumes and fluxes involved in the hydrological cycle. Depending on the meteorological variable or variables of interest, drought is characterized as meteorological, hydrological and agricultural [5].

Hydrological drought is defined as a significant decrease in the availability of water in all its forms appearing in the land phase of the hydrological cycle. Various hydrological variables are used to describe these forms but stream flow is, by far, the most significant variable from the viewpoint of quantity of water. Hence, a hydrological drought episode is related to stream flow deficit with respect to normal conditions.

Indices for characterizing a hydrological drought such as Palmar Hydrological Drought Index (PDHI), Surface Water Supply Index (SWSI) or the index proposed by Palfai in 2002 [6] are, in general, data demanding and computationally intensive. On the contrary, the proposed index SDI keeps advantages of simplicity and effectiveness found in indices of meteorological droughts such as the Standardized Precipitation Index (SPI) ([7], [8] and [9]) or the Reconnaissance Drought Index (RDI) ([10] and [11]). Exclusive use of stream flow is made as the key variable for assessing hydrological drought.

Hydrological draught Indices Based on Stream flow

Stream flow Drought Index (SDI)

$$
S D I_{i . k}=\frac{V_{i, k}-\overline{V_{k}}}{s_{k}}
$$




$$
V_{i . k}=\sum_{j=1}^{3 k} Q_{i, j} \quad i=1,2,3, \ldots . j=1,2,3, \ldots ., 12 k=1,2,3,4
$$

This index SDIi,k requires stream flow volume values Qi,j where i denote the hydrological year and $\mathrm{j}$ denotes month within a hydrological year. We can obtain $\mathrm{Vi}$,k cumulative stream flow volume for the $\mathrm{i}$-th hydrological year and k-th reference period, where Vk and sk are respectively the mean and standard deviation of the cumulative stream flow volumes for the k-th reference period. Definition of states of drought with SDI is shown in the Table 2.

Table 2: Classification of Stream Flow Drought Index (SDI)

\begin{tabular}{|l|l|}
\hline Description of State & Criterion \\
\hline Non drought & SDI $\geq 0.0$ \\
\hline Mild drought & $-1.0 \leq$ SDI $<0.0$ \\
\hline Moderate drought & $-1.5 \leq$ SDI $<-1.0$ \\
\hline Severe drought & $-2.0 \leq$ SDI $<-1.5$ \\
\hline Extreme Drought & SDI $<-2.0$ \\
\hline
\end{tabular}

There are twenty eight (28) catchments cover the whole Langat basin from the origin to its outfall. The combined historical flow from all the catchments were calculated under this study by simulating the calibrated Hydrological model from 25 years from 1985 to 2010 and analyzed to determine the SDI. The SDI is calculated for five different durations such as January-February, March-May, June-August, September to December and January-December. All the calculated SDI is furnished in the Table 3. It is evident from the table that the most extreme drought years are 1998 and 2010 but the 1998 gives the higher SDI for both the dry periods than that of 2010. Considering the SDI, availability of data and model 1998 and 2010 are considered as the extreme drought periods for detailed analysis.

Table 3: Stream Flow Drought Index (SDI) from rainfall runoff

\begin{tabular}{|c|c|c|c|c|c|}
\hline Year & JF & MAM & JJA & SOND & Full Year \\
\hline 1985 & -2.0 & 0.8 & -0.2 & 0.9 & 0.2 \\
\hline 1986 & -0.2 & -0.2 & -0.6 & -0.6 & -0.5 \\
\hline 1987 & -1.0 & -0.6 & -0.1 & 0.8 & 0.0 \\
\hline 1988 & 1.5 & 1.0 & 0.8 & 0.7 & 1.1 \\
\hline 1989 & 0.0 & 0.0 & -0.1 & 0.0 & 0.0 \\
\hline 1990 & -0.2 & -0.5 & -0.5 & 0.7 & 0.1 \\
\hline 1991 & 0.8 & 0.2 & 0.8 & 1.0 & 0.9 \\
\hline 1992 & 0.4 & 0.1 & 1.1 & -0.1 & 0.3 \\
\hline 1993 & 0.5 & 1.0 & 0.6 & 1.3 & 1.1 \\
\hline 1994 & 0.6 & 2.2 & 2.2 & 1.4 & 1.8 \\
\hline 1995 & 1.5 & 1.7 & 1.6 & 1.1 & 1.6 \\
\hline 1996 & 0.5 & 0.2 & 0.0 & -0.7 & -0.2 \\
\hline 1997 & -1.0 & -1.1 & -0.5 & -1.4 & -1.3 \\
\hline 1998 & -1.5 & -2.2 & -1.4 & -1.9 & -2.1 \\
\hline 1999 & -1.0 & -1.0 & 0.1 & -0.5 & -0.7 \\
\hline 2000 & 0.6 & 0.1 & 0.9 & 0.6 & 0.6 \\
\hline 2001 & 1.3 & 0.3 & 0.8 & 0.7 & 0.9 \\
\hline 2002 & -0.5 & -0.2 & -0.1 & 0.5 & 0.1 \\
\hline 2003 & 2.1 & 0.2 & -0.7 & 0.1 & 0.4 \\
\hline 2004 & -0.2 & -0.6 & -1.7 & -2.0 & -1.5 \\
\hline 2005 & -1.8 & -1.2 & -0.8 & -1.0 & -1.3 \\
\hline 2006 & 0.4 & -0.1 & -0.6 & 0.0 & -0.1 \\
\hline 2007 & 1.4 & 0.9 & 1.1 & 0.4 & 0.7 \\
\hline 2008 & -0.2 & 0.6 & 0.2 & -0.5 & -0.1 \\
\hline 2009 & -0.7 & 0.3 & -0.7 & 0.5 & 0.0 \\
\hline 2010 & -0.3 & -2.1 & -2.3 & -2.1 & -2.0 \\
\hline
\end{tabular}

\section{Assessment of Salinity Intrusion}

The extreme drought eventswere selected as 1998 and 2010 and all the models were simulated for those periodsto assess the salinity level in the Langat river system. In addition to that the model was simulated for 2009 (normal condition) and also for no flow from upstream. Figure 6 shows salinity variation from the outfall of Sungai Langat to Dengkil at different hydrological event. In the normal condition (2009) 1 ppt saline line moves up to $33 \mathrm{~km}$ from the mouth of the river whereas in the year 1998 it moves up to $34 \mathrm{~km}$ which is one kilometer more from normal condition. But in case of zero flow at the upstream boundary 1 ppt saline line moves up to $42 \mathrm{~km}$ which is about 9 kilometer more from normal condition. It is also evident from the model 
results that both the year 1998 and 2010 show almost the same salinity level as both of them represent almost the same drought condition.

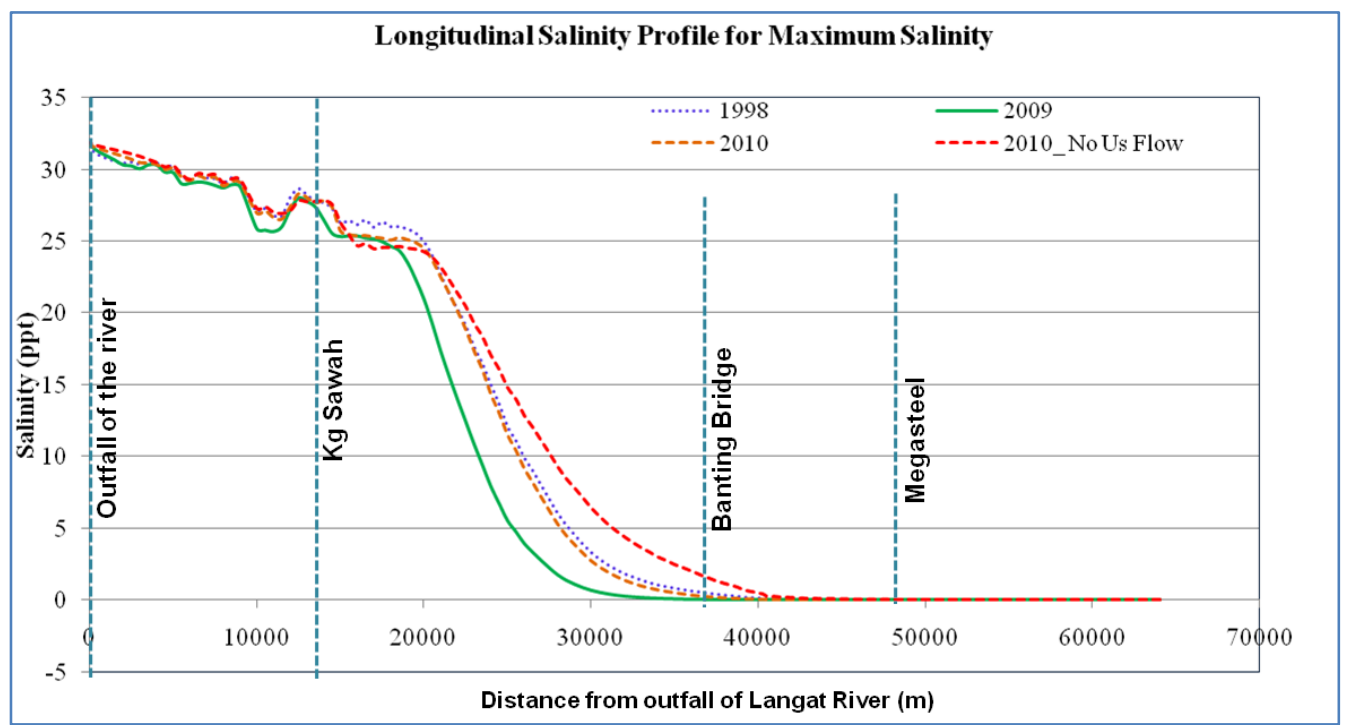

Figure 6: Variation of salinity level along Langat River from outfall towards land

\section{Conclusion}

The main objective of this research is to establish the extreme drought event in Langat river basin and its consequence on salinity intrusion through Langat River. Historical rainfall data of all the stations were analyzed and simulated through hydrological model to produce runoff for a period of 25 years from 1985 to 2010 and analyzed for extreme drought event. It is clear from the study findings that the year 1998 and 2010 are the extreme drought events for the Langat river basin. In addition to that hydrodynamic and salinity model were also developed under this study to assess the impact on salinity intrusion during extreme drought event. It is also evident from the simulation results that Langat River is not that much vulnerable on salinity intrusion problem during extreme drought event but if there is no rainfall from upstream the $1 \mathrm{ppt}$ saline line may intrude more $9 \mathrm{~km}$ towards upstream.

\section{Acknowledgement}

This study was funded by Jurutera Perunding Zabba SDN. BHD., a private organization in Malaysia and carried out by Institute of Water Modelling (IWM) in Bangladesh. The authors express their gratitude to IWM for the support to use the study findings in the paper.

\section{References}

[1]. H. Juahir, S.M. Zain, A.Z. Aris, M.K. Yusof, M.A.A. Samah and M.B. Mokhtar, Hydrological Trend Analysis Due to Land Use Changes at Langat River Basin, Environment Asia 3 (special issue, 2010, pp 20-31

[2]. Climate Ark. Malaysian state begins water rationing amid dry spell 2002(cited 23 July 2008): Available from: http://www.climateark.org/.

[3]. M. Angela, No Water Rationing in Klang Valley, in The Sun. 2002: Shah Alam

[4]. O. C. Austin, Risk in Malaysia Agriculture: The need for a strategic approach and a policy refocus, Kaijan Malaysia, Vol. 30, No. 1, 2012, 21-50

[5]. M.A. Beran and J.A. Rodier, Hydrological aspects of drought: A contribution to the International Hydrological Programe (Paris and Geneva, UNESCO, 1985)

[6]. I. Pafai, Probability of drought occurrence in Hungary. (edition of Hungarian Meteorological Service); 106 (3-4), 2002, 265-275

[7]. T.B. McKee, N.J. Doesken and J. Kleist, The relationship of drought frequency and duration to time scales. $8^{\text {th }}$ Conference on Applied Climatology, 1993, pp. $179-184$

[8]. G. Tsakiris and H. Vangelis, Towards a drought watch system based on spatial SPI, Water Resources Management, 2004

[9]. A. Cancelliere, Di Mauro, B. Bonaccorso and G. Rossi, Drought forecasting using the Standardized Precipitation Index. Water Resources Management, 21 (5), 2007, 801 - 819

[10]. G. Tsakiris and H. Vangelis, Establishing a drought index incorporating evapotranspiration, European Water, 2005

[11]. G. Tsakiris, D. Pangalou and H. Vangelis, Regional drought assessment based on the Reconnaissance Drought Index (RDI), Water Resources Management, 200, Online First (DOI: 10.1007/s 11269-006-9105-4), Springer Netherlands. 